\title{
Nan-ji-xian-weng: the God of Longevity
}

\author{
Huei-Shyong Wang • Meng-Fai Kuo
}

Published online: 16 April 2009

(C) Springer-Verlag 2009

Perpetual rejuvenation was the dream of many emperors in ancient China. They asked the Taoist priests to pursue the pill of immortality, however, they never made it. People started to entrust themselves to the constellations. Twentyeight constellations make up the main component of the

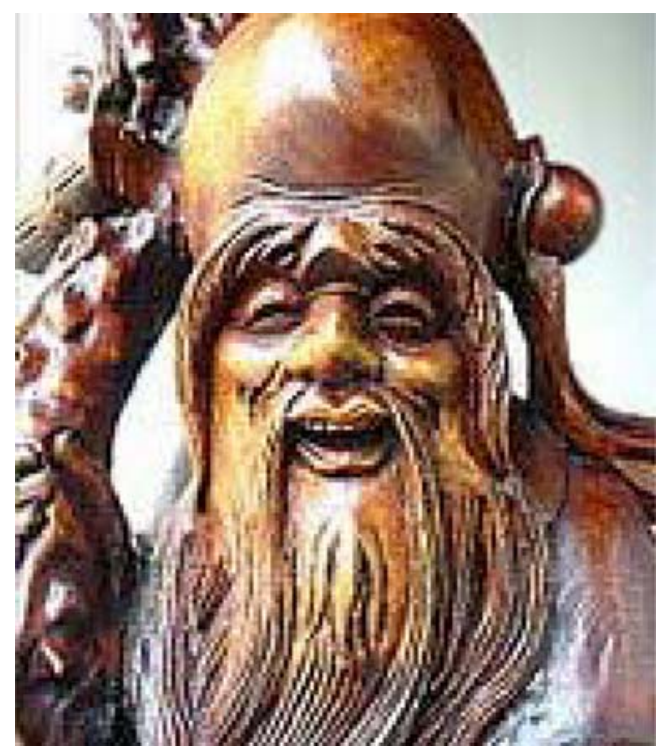

Fig. 1 The typical picture of Nan-ji-xian-weng with a prominent forehead, long eyebrow and a cane (adapted from a sculpture on website: http://goods.ruten.com.tw/item/history?10060907647774\#pic)

H.-S. Wang

Division of Pediatric Neurology, Chang Gung Children's Hospital, Chang Gung University College of Medicine,

Taoyuan, Taiwan

\section{M.-F. Kuo $(\square)$}

Division of Neurosurgery, Department of Surgery,

National Taiwan University Hospital and National Taiwan

University College of Medicine,

7 Chung-Shan South Road,

Taipei, Taiwan

e-mail: mfkenator@gmail.com
Star District System created by ancient Chinese. They divided the astrospace near the ecliptic into 28 districts. Each district is nominated as one constellation. The first two constellations, the leading stars, are regarded as the 'God of Longevity'. It is also called 'Nan-ji-xian-weng'.

According to Chinese folk legends, 'Nan-ji-xian-weng' has a special appearance. He is an old man beaming with a broad smile. His forehead is bossing. Sometimes, there is bitemporal bossing, too. He has long ears and eyebrow hair (Fig. 1; http:// goods.ruten.com.tw/item/history?10060907647774\#pic, accessed 03/12/2009). He likes to hold a cane and carries a birthday peach with him. He uses the deer and crane for land and air transportations, respectively (Fig. 2; http://www. epochtimes.com/b5/2/5/20/n191188.htm, accessed 03/12/

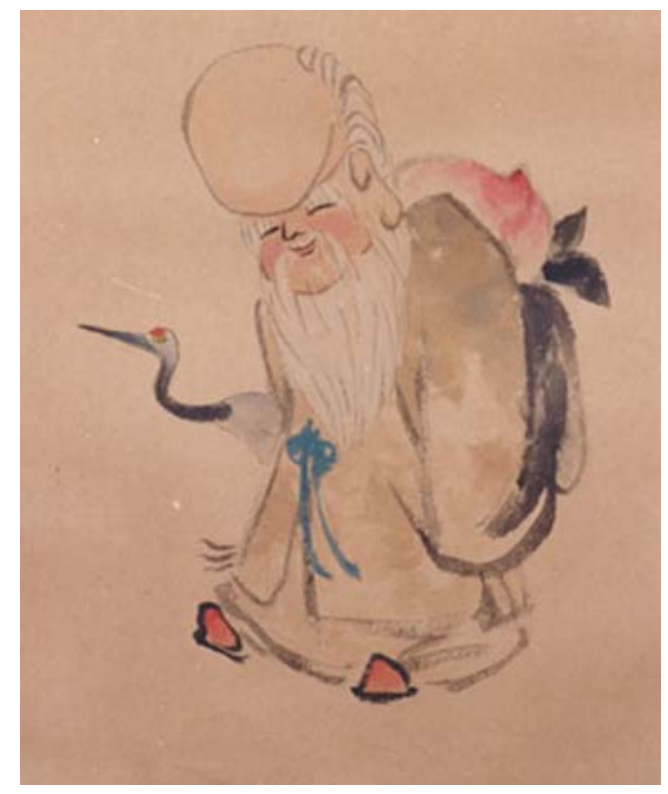

Fig. 2 An unusual head. The work of a famous Chinese lady artist, Cuiying Zhang, showing Nan-ji-xian-weng carrying a birthday peach with him, a symbol of longevity. The crane helps him to travel in the air (adapted from the website: http://www.epochtimes.com/b5/2/5/20/ n191188.htm). This figure is used as cover illustration 
2009). The long ears, eyebrow hair, cane, peach, and crane are symbols of longevity. The deer is a symbol of a feudal title.

The frontal and sometimes associated bitemporal bossing on the drawings and sculptures of Nan-ji-xian-weng looks similar to the pictures of patients with craniosynostosis. It is interesting that in ancient Chinese folks, the other associated abnormalities with craniosynostosis were never mentioned since Nan-ji-xian-weng is the God of Longevity. Some legends say that the frontal mass is a soft tissue tumor instead of a bony lesion. As 'Nan-ji-xian-weng' has been living for as long as the earth, the mass should be a benign slowgrowing tumor. 